\title{
A contribuição do Serviço Social para a efetivação do Controle Social no HC-UFU
}

\author{
The contribution of Social Service for the effectiveness \\ of Social Control in HC-UFU
} Priscila Aparecida Martins*

\begin{abstract}
Resumo - O presente estudo refere-se à pesquisa realizada na Residência Multiprofissional em Saúde do Hospital de Clínicas da Universidade Federal de Uberlândia (HC-UFU), na área de Atenção ao Paciente em Estado Crítico, entre 2012 e 2014 (período em que foi cursada a residência multiprofissional pela pesquisadora). Objetiva discutir a contribuição que os/as assistentes sociais, empregados(as) nas unidades de Clínica Médica, Unidade de Terapia Intensiva e Pronto-Socorro, podem oferecer para a efetivação do Controle Social no interior do HC-UFU, a partir da análise documental, observação empírica e pesquisa de campo.

Palavras-chave: controle social; participação popular; serviço social; política de saúde.
\end{abstract}

\begin{abstract}
This study refers to research conducted in a Multidisciplinary Residency Clinics Hospital of Health of the Federal University of Uberlândia (HC-UFU) in the area of Attention to Critical Patient State between 2013-2014 (the time was study comprises the multi-residence by the researcher). Aims to discuss the contribution that / social workers, employees / in the Clinical units, Intensive Care Unit and Emergency Department can offer for the realization of social control, within the HC-UFU, from the document analysis, observation empirical and field research.

Keywords: social control; popular participation; social service; health policy.
\end{abstract}

\section{Introdução}

Este estudo partiu de reflexões que envolvem as ações do Serviço Social na mobilização popular para a efetivação do Controle Social na área de Atenção ao Paciente em Estado Crítico (Apec) do Hospital de Clínicas da Universidade Federal de Uberlândia (HC-UFU). Foi realizado por uma

\footnotetext{
* Assistente Social graduada pela Universidade Estadual Paulista (UNESP), Residente Multiprofissional em área da Saúde pela Universidade Federal de Uberlândia (UFU). Correspondência: Rua Antônio Mathias, 439, Vila Exposição, Franca-SP. CEP: 14-407-453. E-mail: <pryscylla.r@hotmail.com>
} 
residente de Serviço Social inserida na área de concentração Atenção ao Paciente em Estado Crítico (Apec) do HC-UFU.

O hospital, conforme a hierarquização do Sistema Único de Saúde (SUS), está categorizado como referência em média e alta complexidade e sua abrangência compreende 30 municípios, que compõem as macro e microrregiões do Triângulo Mineiro Norte. Atualmente, conta com 510 leitos e atende uma população de quase três milhões de usuários de Uberlândia e região (UFU, 2010b).

De acordo com informações prestadas pelo Conselho Municipal de Saúde de Uberlândia (CMSU), a cidade ainda conta com 14 Conselhos de Saúde, entre locais e distritais, mais o municipal. O CMSU possui composição paritária de seus membros, com 28 membros titulares, sendo 14 representantes do setor governamental, entre prestadores de serviços e trabalhadores da saúde, e 14 representantes dos usuários, agregando ainda 28 membros suplentes dos mesmos segmentos.

O recorte deste estudo sobre o Controle Social envolve a contribuição que o/a ${ }^{1}$ assistente social, inserido(a) nas enfermarias que compõem a Apec, pode oferecer por meio do trabalho para a sua efetivação no HCUFU. Isto, pois o Serviço Social, enquanto profissão que busca a efetivação dos direitos e atua numa perspectiva socioeducativa ${ }^{2}$, tem o dever de orientar os usuários dos serviços de saúde sobre a relevância que a participação popular assume no monitoramento e na avaliação da política de saúde por meio do Controle Social.

Entretanto, a realização deste trabalho no ambiente hospitalar, principalmente nas áreas que atendem casos de urgência e emergência, pode ser considerada um grande desafio devido à crescente demanda e à "imediaticidade" dos atendimentos, que dificultam a possibilidade de um trabalho contínuo e de base reflexiva.

Este estudo objetiva contribuir para a reflexão sobre a efetivação do Controle Social no HC-UFU, envolvendo as ações do Conselho de Integração HC-UFU- Sociedade ${ }^{3}$, o Conad $^{4}$ e a Ouvidoria do HC-UFU.

Com relação à pesquisa de campo, optou-se por fazer a análise dos dados pela abordagem qualitativa, a qual, conforme Minayo (1999), tem seu estudo voltado a um campo que não pode ser quantificado, pois expressa as relações sociais, seus valores, significados etc.

\footnotetext{
${ }_{1}^{1} \mathrm{Na}$ construção do texto, foi utilizada a variação de gênero para se referir aos/às profissionais do Serviço Social, conforme às alterações estabelecidas no Código de ética profissional do(a) assistente social de 1993 (CFESS, 1993).

2 " [...] as ações socioeducativas e/ou educação em saúde não devem pautar-se pelo fornecimento de informações e/ou esclarecimentos que levem a simples adesão do usuário, reforçando a perspectiva de subalternização e controle dos mesmos. Devem ter como intencionalidade a dimensão da libertação na construção de uma nova cultura [...]." (CFESS, 2009, p. 55).

${ }^{3}$ Órgão consultivo que tem como objetivo servir de espaço para a interlocução de vários setores do HC-UFU com a sociedade (UFU, 2010).

${ }^{4}$ Órgão normativo e deliberativo que tem a função de aprovar projetos, programas e planos de ação, estabelecer as normas gerais para a assistência médico-hospitalar, de pesquisa, de cooperação didática e de prestação de serviços médicos e hospitalares à comunidade etc. (UFU, 2010).
} 


\section{O Controle Social na política de saúde}

A participação popular nas diversas políticas sociais existentes é identificada como Controle Social e pode ser considerada um dos eixos estruturantes da Política Nacional de Saúde, pois respalda as ações dessa área na Constituição Federal de 1988, na Lei no ${ }^{0} .142$, bem como na Política Nacional de Promoção da Saúde (BRASIL, 1988).

No presente estudo, optou-se por partir do marco legal vigente que demarca a obrigatoriedade do exercício do Controle Social, ou seja, a Lei no 8.142, de 1990 (SUS) e a Constituição Federal de 1988.

Dentre as instâncias de Controle Social delimitadas pela Lei $n^{\circ}$ 8.142/90, há os Conselhos de Saúde que, segundo Correia (apud LOURENÇO, 2009), podem ser caracterizados como espaços democráticos de gestão. Estes, mesmo com suas contradições e fragilidades, possuem significativa relevância, especialmente no Brasil, onde a maioria da população tem enraizada a cultura de submissão devido ao seu desenvolvimento histórico.

Atualmente, a existência e o funcionamento dos Conselhos de Saúde são um dos pré-requisitos para que os municípios e os estados estejam vinculados ao SUS e recebam os recursos destinados à saúde (BRASIL, 1990b).

As conferências, por sua vez, são fóruns de debates e participação objetiva da população usuária e das organizações. Devem ser entendidas como espaços de discussão pública que reúnem representantes de diversos segmentos sociais. Ocorrem de quatro em quatro anos em cada esfera do governo para avaliar as ações em saúde e estabelecer as prioridades de que a sociedade necessita, sendo atendida com mais agilidade (BRASIL, 2010).

Outro mecanismo oficial que pode atuar no Controle Social é a Ouvidoria Geral do SUS, que está vinculada ao Departamento de Ouvidoria Geral do Sistema Único de Saúde (Doges), criado no ano de 2003, e integra a Secretaria de Gestão Estratégica e Participativa (SGEP) do Ministério da Saúde (MS). O acesso a este mecanismo pode ser realizado pela internet, a partir do Portal do Ministério da Saúde, pelo telefone do Disque Saúde (136) ou através dos Correios (BRASIL, 2014).

\section{O Serviço Social e o Controle Social na área da saúde}

O Serviço Social, enquanto profissão que se propõe a lutar ao lado da população em defesa de seus interesses e a buscar a efetivação dos direitos sociais, conforme o Código de ética profissional (CFESS, 1993), trabalha para o aprofundamento da democracia e da ampliação da participação política. Tem, ainda, o dever de contribuir para que o Controle Social seja efetivo. No entanto, no ambiente hospitalar, o trabalho do(a) 
assistente social fica preso, diversas vezes, à realização de orientações individualizadas com caráter imediatista, fato também enfatizado na pesquisa de Ana Maria Vasconcelos $(2009)^{5}$, na cidade do Rio de Janeiro.

Além do mais, conforme o setor em que o profissional do Serviço Social esteja inserido, não há espaço físico adequado para a criação de grupos de discussão acerca dos direitos dos usuários, de reflexão sobre as condições em que se encontram os usuários do serviço, entre outros, nem tempo disponível para tal. Tampouco há disposição dos familiares ou pacientes para a realização de trabalhos deste tipo ou de outros tipos, neste mesmo sentido. Dessa forma, de acordo com Ana Maria Vasconcelos (2009), muitas vezes as demandas apresentadas pelos usuários são reduzidas a problemas particulares, inviabilizando a busca pela leitura da totalidade da situação e o fortalecimento da mobilização popular.

Por isso, é necessário que o profissional do Serviço Social, dentro das condições objetivas e subjetivas de trabalho, crie estratégias para que, junto à equipe multiprofissional, possa colaborar na efetivação do Controle Social. Portanto, conforme os Parâmetros de atuação do assistente social na área da saúde ${ }^{6}$, cabe aos profissionais do Serviço Social, dentre outras atribuições, desenvolverem ações voltadas para a mobilização e participação social de usuários, familiares, trabalhadores da saúde etc. (CFESS, 2010). Sendo assim, destaca-se que toda ação profissional do(a) assistente social deve ser obrigatoriamente permeada pelo trabalho socioeducativo no sentido de colaborar para a efetividade do Controle Social.

No entanto, sublinha-se que a motivação da comunidade, no que se refere às ações envolvidas com o Controle Social, é um desafio ainda maior nas unidades de atendimento de alta complexidade, se comparadas às unidades de atendimento de atenção básica. Isto pois, nestas, o contato com a população usuária é contínuo e, geralmente, as condições de saúde dessas pessoas estão menos debilitadas, além do fato de que, na maioria das vezes, elas residem em localidades próximas, ao contrário do que acontece nas unidades de atendimento de alta complexidade.

\section{O Controle Social no HC-UFU e o Serviço Social}

Os espaços destinados ao Controle Social, especificamente no HCUFU atualmente, estão previstos em três vias diferentes, sendo uma delas o Conselho de Integração HCU-Sociedade. Funciona como um órgão consultivo e tem como objetivo servir de espaço para a interlocução de vários setores do HC-UFU com a sociedade.

O Regimento Interno do HC-UFU, em vigência desde o ano de 2010, aponta como atribuições do referido conselho o acompanhamento às políticas assistenciais e de formação de recursos humanos na área da saúde, bem como o exame das demandas existentes na sociedade. A partir 


\section{nevistg am pautg}

\} A CONTRIBUIÇÃO DO SERVIÇO SOCIAL PARA A EFETIVAÇÃO DO CONTROLE SOCIAL - MARTINS P. A. \}

da leitura realizada com essas ações, deve sugerir parcerias e atividades a serem desenvolvidas, na tentativa de sanar as questões de seu âmbito de atuação.

O Conselho de Administração (Conad), outra instância ligada ao acompanhamento das ações administrativas do HC-UFU, também é parte integrante do Controle Social do hospital. É composto por representantes de vários segmentos e tem função normativa e deliberativa no que se refere a aprovar projetos, programas e planos de ação, estabelecer as normas gerais para a assistência médico-hospitalar, a pesquisa, a cooperação didática e a prestação de serviços médicos e hospitalares à comunidade, disciplinar a rotina administrativa, atuar como instância de recurso, além de elaborar e aprovar o regimento interno (UFU, 2010).

Outra via que colabora para o Controle Social dentro HC-UFU é o serviço de Ouvidoria, que tem a função de dar voz aos usuários dos serviços prestados, funcionando como uma central de atendimento pronta para receber reclamações, solicitações, elogios, sugestões e denúncias referentes ao atendimento no interior do hospital. Assim, tomar as medidas necessárias para o encaminhamento das questões que surgirem, oferecendo uma devolutiva ao demandante e/ou à comunidade.

Em relação aos/às profissionais de Serviço Social que responderam à pesquisa, estes se graduaram em uma faculdade privada da cidade de Uberlândia. Alguns possuem pós-graduação lato sensu e/ou stricto sensu tanto na área da saúde quanto em outras áreas. Eles possuem de nove a vinte anos de formação, são funcionários no hospital entre três e oito anos, não têm outro vínculo empregatício e trabalham 30h semanais.

Durante as entrevistas, percebeu-se que, mesmo com as particularidades encontradas em cada local (Clínica Médica, UTI e Pronto-Socorro), a rotina de trabalho tem o mesmo foco, ou seja, a realização de encaminhamentos diversos, conforme a demanda e a ação socioeducativa:

A rotina de trabalho nas enfermarias consiste em acolhimento dos pacientes ingressantes, onde a gente faz a coleta de dados, de informações, de contatos de familiares, informações referentes aos motivos da internação, informações referentes às condições sociais para tentar detectar se existe algum problema social ou familiar para poder estar encaminhando aos profissionais responsáveis, e dou também segmento aos pacientes que já estão internados aguardando cirurgia ou recuperando de cirurgia, dando apoio, durante esse processo de internação e recuperação de cirurgia, apoio socioeducativo. (Arnaldo ${ }^{7}$ assistente social da Enfermaria).

\footnotetext{
${ }^{5}$ Estudo realizado pela assistente social Ana Maria Vasconcelos sobre a atuação dos assistentes sociais na rede de saúde do município do Rio de Janeiro no ano de 2009.

${ }^{6}$ Documento que serve como parâmetro para o exercício profissional dos(as) assistentes sociais na área da saúde, criado em 2010 pelo CFESS.

${ }^{7}$ Todos os nomes referidos nos comentários dos entrevistados são fictícios. Além disso, o gênero apresentado não corresponde necessariamente ao dos participantes. Tal condição foi promovida com o intuito de preservar a identidade dos sujeitos de pesquisa, conforme orientações da Resolução 466/12 Conep.
} 
É, na UTI hoje o Serviço Social atua atendendo as famílias dos pacientes internados que na maioria estão impossibilitados de conversar. Às vezes, eles estão sedados e aí não dá para a gente fazer uma abordagem com eles. Aí a gente atende as famílias, verifica quais são as demandas necessárias e quando o paciente tem possibilidade de conversar... nós também fazemos isso, fazemos o mesmo atendimento com ele para saber a demanda, o que ele precisa, o que aconteceu, conhecer a história dele para saber em que a gente pode intervir... é isso na UTI adulto, lá a gente faz discussão de caso também com a equipe multiprofissional, quando necessário, para atender a uma demanda específica e a rotina maior da UTI hoje é o óbito. [...]. (Maria assistente social da Enfermaria)

Minha rotina de trabalho? Eu trabalho no setor de urgência e emergência, no Pronto-Socorro, das $13 \mathrm{~h}$ às $19 \mathrm{~h}$, às vezes eu venho no plantão noturno ou nos finais de semana. E no setor de urgência e emergência a gente atende a família dos pacientes acidentados, violência de crianças, de mulheres, de idosos, todos os tipos de violência e alta, as altas, apoio às famílias... enfim, são várias atividades. (Antônio assistente social do Pronto-Atendimento).

No que se refere ao Controle Social, os/as assistentes sociais enfatizam a participação da comunidade nas tomadas de decisões como forma de qualificar e fiscalizar os serviços de saúde. Sua efetivação foi apontada como um canal de comunicação entre os usuários e os gestores, a fim de que seus direitos sejam de fato respeitados.

O Controle Social seria a participação da sociedade, da comunidade, dentro das ações dos equipamentos sociais e dos serviços oferecidos, eu entendo isso. É a sociedade interagindo para fiscalizar, participar e opinar. (Arnaldo - assistente social da Enfermaria).

No entanto, na prática eles(as) acreditam que este Controle Social ainda está bem distante de ser efetivo, pois falta informação, formação, motivação dos representantes políticos em capacitar a população nesse aspecto, bem como iniciativa dos equipamentos prestadores de serviço, como o HC, na mobilização dos funcionários em defesa desta causa.

O Controle Social eu acho que é muito falho porque a população não participa efetivamente como deveria participar. Aqui na UF̧, por exemplo, a gente não participa de nenhuma. O Serviço Social não tem participado de nada do Controle Social. Enquanto eu estava na prefeitura até que a gente participava, mas aqui, realmente... desde que eu entrei vai fazer nove anos e eu nunca participei de nada. (Antônio - assistente social do Pronto-Atendimento).

Os profissionais acreditam que a falta de formação, de divulgação e de mobilização a respeito do Controle Social são pontos de extrema re- 


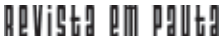

\} A CONTRIBUIÇÃO DO SERVIÇO SOCIAL PARA A EFETIVAÇÃO DO CONTROLE SOCIAL - MARTINS P. A. \}

levância a serem superados, pois funcionam como uma espécie de entrave na efetivação do Controle Social. Um(a) dos(as) assistentes sociais também ressalta que são poucos os participantes destes espaços e muitos o fazem com objetivo de satisfazer interesses pessoais:

Eu acho que falta divulgação para que as pessoas se interessem e eu vejo muito esses Conselhos também como um cabide pra pessoa ganhar visibilidade, porque geralmente são líderes de bairro ou representantes de bairro. E esses representantes de bairro, eles vislumbram conseguir se tornarem vereadores. Então, em minha opinião, eu vejo como um cabide para eles conseguirem se tornar vereadores. Isso... e como deveria ser, deveria ser efetivo na luta pela melhoria da qualidade da saúde, principalmente do sistema SUS, o que não acontece. (Arnaldo - assistente social da Enfermaria).

Um aspecto de extrema relevância destacado por um(a) dos(as) assistentes sociais entrevistados(as) é a não participação da comunidade no Controle Social devido ao receio de represálias, fato que se faz perceptível no cotidiano de trabalho desses profissionais:

Assim, eu percebo que aqui, com relação ao Controle Social, a população, ela não tem muita abertura porque, por mais que ele vai reclamar, ele nunca tem o direito dele atendido e ele acaba se omitindo. Por mais que o Serviço Social instrua, entre na Promotoria, procure a Defensoria Pública, a população tem medo de depois não ser recebida novamente, então ele prefere se omitir. Eu acho que aqui não tem esse fortalecimento por parte de toda a equipe pra que o usuário entenda que é um direito dele e que se reclama, se ele luta, aqui dentro do hospital, fora, no município de Uberlândia ou nos outros municípios, ele não vai ser punido por isso. Eles têm muito medo da punição, de depois não ser atendido, então eles não entendem, eles tểm desconhecimento e mesmo quando a gente explica eles preferem se omitir. (Arnaldo assistente social da Enfermaria).

Diante dessa situação, indagou-se a respeito de alguma ação no trabalho que esses(as) assistentes sociais realizam. O intuito era estimular o Controle Social no interior e/ou exterior do HC, e as respostas obtidas seguem a perspectiva apresentada pela assistente social Maria:

Eu acho que nós, enquanto assistentes sociais, na rotina de trabalho, influenciamos para que isso aconteça, mas como rotina de trabalho, até porque a gente tem uma ética a seguir, um comprometimento com o usuário; a gente tem um comprometimento com o hospital também, e como o hospital não trabalha, pelo menos não é visto hoje dentro da política dele um incentivo para que a gente faça o Controle Social, eu não vejo que fora da rotina do Serviço Social, das orientações que o assistente social já tem que fazer, que tenha isso dentro do hospital, não percebo não, não vejo. Acho que nós 
fazemos pelo simples fato de atuar, né?! [...], mas que o hospital dá caminhos para que a gente oriente a todos trabalharem nessa política acho que não, posso estar enganada, mas eu acho que não. Para o Serviço Social é mecânico, faz parte da nossa função, mas não o hospital. Acho que não. (Maria - assistente social da Enfermaria).

Dessa forma, fica claro que para esses(as) funcionários(as) não há incentivo por parte do $\mathrm{HC}$ no sentido de estimular o Controle Social ${ }^{8}$. Porém, duas assistentes pontuaram que esse Controle Social é intrínseco ao trabalho profissional por meio das ações socioeducativas, uma vez que, se o trabalho do(a) assistente social é buscar a efetivação de direitos, procurando inclusive o "empoderamento" dos sujeitos, naturalmente perpassa pelo campo da mobilização popular na efetivação do Controle Social.

Ainda sobre esse assunto, questionou-se acerca da articulação com outros profissionais no sentido de fortalecer a participação dos trabaIhadores da saúde nos espaços de Controle Social. As respostas relatam que não; no interior do hospital cada profissional trabalha de maneira individual e são separados por categorias. Mesmo no atendimento multiprofissional não há muito envolvimento nesse sentido. Conforme um(a) dos(as) entrevistados(as), de acordo com a demanda do usuário pode até haver contato com outros profissionais, mesmo fora do hospital, mas de maneira muito imediata e sem muita perspectiva de colaborar com essa questão.

Poderia ser, mas hoje não é uma realidade, não vejo, não vejo essa articulação, aí quando você fala 'outros profissionais' a gente entende também que não só do Serviço Social, né?! E hoje, aqui dentro do hospital, é muito em bloco as profissões, cada um está trabalhando no seu direcionamento, a enfermagem no seu, a equipe médica no seu, a psicologia, o Serviço Social, apesar de a gente atender casos específicos em equipe multiprofissional, mas no geral para articular essas ações eu acho que não. Até porque não tem nenhuma política dentro do hospital que incentive isso, para que a gente trabalhe nesse sentido para atender melhor o paciente, não é incentivado isso. (Maria - assistente social da Enfermaria).

Com o objetivo de compreender qual a percepção imediata que os usuários das enfermarias de Clínica Médica, UTI e Pronto-Socorro têm sobre o Controle Social, foi entrevistado, aleatoriamente, um paciente internado para cada espaço que compõe a Apec. A realização das entrevistas veio ao encontro das afirmações realizadas pelos(as) profissionais do Serviço Social, demonstrando bastante desconhecimento por parte dos usuários do serviço sobre este tema: "Sei, Controle Social é mexer com o povo, o social, não é?!" (Anderson - Enfermaria).

\footnotetext{
${ }^{8}$ De acordo com a Portaria Interministerial n. 2.400, de 02 de outubro de 2007, são previstos espaços de participação de docentes, discentes, de funcionários e de usuários para a efetivação do Controle Social nos Hospitais de Ensino (BRASIL, 2007).
} 


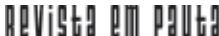

\} A CONTRIBUIÇÃO DO SERVIÇO SOCIAL PARA A EFETIVAÇÃO DO CONTROLE SOCIAL - MARTINS P. A. |

Sendo assim, apenas uma usuária fez considerações sobre a possibilidade de o/a assistente social contribuir na efetivação do Controle Social; os outros dois, apesar de imaginarem que exista alguma relação, não conseguiram elaborar argumentações a este respeito:

Às vezes eu acho que sim, acho que pode através de conversa, né?! De estar conversando, né?! Incentivando a população a estar participando, para poder ver o que está acontecendo, né?! (Rosa - ProntoAtendimento).

Por outro lado, com o intuito de conhecer as instâncias de Controle Social presentes no $\mathrm{HC}$ e sua dinâmica de funcionamento, confrontando com a realidade apresentada, foram entrevistados um representante da Ouvidoria do $\mathrm{HC}$ e um membro do Conad, bem como um membro do extinto Conselho de Integração UFU-Sociedade. Eles pontuaram o que entendem por Controle Social:

Controle Social, vamos ver o que eu compreendo por Controle Social? A ação da Secretaria de Saúde em dar autonomia para o hospital para resolver aqui imediatamente, por quê? É como houve uma relação falando que a partir do momento em que a Secretaria de Saúde tomou posse de todos os agendamentos não tem Controle Social por quê? O povo vem de fora, procura assistência aqui e não pode, tem que voltar para cidade dele para poder conseguir as coisas e nós precisávamos ter o hospital como uma pactuação do SUS, que devia ter autonomia para resolver o caso das pessoas, eu entendo isso. E da saúde eu acho que tem que haver uma grande melhoria, mudar tudo. (Oscar $\left.\operatorname{ICS} 1^{9}\right)$.

Na verdade é algo sublime porque é a representação da sociedade no controle de tudo que é gasto com dinheiro público, principalmente nesse caso, na saúde, né?! Então, o Controle Social é os olhos de tudo que acontece de fato sem nenhuma venda. (Isaías - ICS2).

O que eu compreendo por Controle Social é isso, é a participação de cada ente nessa ação, de fazer, poder opinar, poder levar a sugestão, dar a contribuição, não só ficar esperando a melhoria, eu sou membro, eu sou partícipe, eu preciso emitir a minha opinião, minha sugestão, para dar uma contribuição. Qual que vai ser a melhoria? Tem 'a meIhoria poderia ser isso', então dar sugestões concretas, 'olha essa ação', eu entendo esse um papel do Controle Social, essa ação mesmo que envolve todos sem uma responsabilidade, sem falar assim, 'olha, aqui tem um assento garantido para $x, y^{\prime}$, não, aberta que às vezes

\footnotetext{
${ }_{9}^{9}$ Nos depoimentos prestados pelos membros do Conselho de Integração UFU-Sociedade, Conad e Ouvidoria do HCUFU, a pesquisadora utilizou as legendas ICS1, ICS2 e ICS3, ou seja, Instâncias de Controle Social 1, 2 e 3, não apresentadas necessariamente nesta ordem, com o objetivo de preservar a identidade dos participantes, conforme orientações da Resolução 466/12 Conep.
} 
você tem uma sugestão, uma pessoa que você imagina que é a menor, a que tem um menor índice de qualificação, às vezes, uma sugestão é que vai ser a cereja do bolo. (Madalena - ICS3).

Desta forma, infere-se que alguns dos entrevistados atribuem ao Controle Social a tarefa já elucidada pelos(as) profissionais de Serviço Social e pelas explanações apresentadas. No entanto, um deles permanece limitado às questões burocráticas que, ainda que sejam relevantes, não podem ser identificadas como as únicas ações que compõem o conceito de Controle Social.

Por outro lado, solicitou-se que os entrevistados participantes das instâncias de Controle Social do HC explicassem um pouco sobre a finalidade e o funcionamento dos espaços a que pertencem:

A ICS1 tem como objetivo a humanização do trabalho oferecido pelo hospital e o pessoal vem nos procurar justamente no momento de necessidade, de agonia, para resolver o problema, só que a ICS1 não tem função resolutiva. Nós somos ouvidores, acatamos as manifestações das pessoas e as encaminhamos às pessoas que têm poder pra resolver. (Oscar ICS1).

São feitas reuniões esporádicas, porém não é enviado material prévio, nem entregue material posteriormente, nem feito leitura da ata. (Isaías - ICS2).

A ICS3, essa ICS3 aqui no hospital funciona de forma paritária onde tem membros de iguais instâncias, então tem um número da sociedade e um número de trabalhadores do hospital, e ele é constituído para o efeito do Controle Social de partes iguais. Então tem 50\% da comunidade e $50 \%$ de trabalhadores do hospital. (Madalena - ICS3).

Partindo destas considerações, os referidos representantes foram questionados se entendem os espaços em que atuam como Instâncias de Controle Social.

Ela teria que ter força para isso, mas não tem poder resolutivo. (Oscar ICS1).

Não, ele ainda precisa mudar muito para que realmente seja um Controle Social de fato, porque ele é mais informativo e comunicativo do que está acontecendo do que fiscalizador, resolutivo. Então eu não vi lá dentro, pela minha experiência de Controle Social, eu não vi lá dentro nada que assemelhe a um Controle Social, muito pelo contrário. (Isaías - ICS2).

Sim, ele exerce essa forma de Controle Social justamente por isso, porque ele tinha uma percepção de que é importante, fazer esse elo entre a comunidade e a universidade. Essa comunidade, ela era tanto 
acadêmica como comunidade, porque muitas vezes é entendia que precisava de mostrar para a comunidade o que que acontecia dentro do hospital porque, muitas vezes, a comunidade só passa a saber das dificuldades, dos problemas do que acontece quando aparece no jornal ou quando aparece num noticiário, 'olha aconteceu isso na Medicina', 'olha, aconteceu isso', então a proposta da ICS3 era fazer essa integralização e socialização das ações [...]. (Madalena - ICS3).

Estas falas trazem a ideia de que os locais citados são reconhecidos como espaços de Controle Social, no entanto, não conseguem atingir tal objetivo, como destacaram Oscar e Isaías. Para eles, a realidade ainda está muito distante desta condição. Já Madalena defende que o espaço do qual faz parte exerce o Controle Social, e ilustra seu ponto de vista com um relato de manifestação realizada no seu interior.

Seguindo com as interrogações, a próxima questão levou Isaías a revelar se participa de outros espaços destinados ao Controle Social:

Sim, participo de Conselhos locais de saúde nas periferias, Conselhos distritais, mais especificamente do setor oeste, que é onde eu sou presidente do Conselho, participo no Conselho Municipal de Saúde e das comissões de saúde. Eu estou hoje na de urgência e emergência e dos assuntos jurídicos, e ontem eu entrei também para de vigilância sanitária, que é sobre os animais. (Isaías - ICS2).

No decorrer da entrevista, novas inquietações emergiram à medida que a fala dos entrevistados apresentou novos pontos importantes para este debate. Por conseguinte, segue uma contribuição da experiência de fragilidade do Controle Social verificada no discurso dos entrevistados em outros espaços de participação popular:

Então, lá realmente, principalmente os Conselhos locais e distritais e até mesmo do municipal, é o Controle Social, porque a gente apresenta todas as demandas que as pessoas estão precisando, igual no meu caso, eu represento o usuário e a gente discute essas demandas, a gente faz fiscalização, se há denúncias, por exemplo, de erros em atendimentos nas unidades, a gente vai atrás. A gente é que faz recomendação para a gestão para que acerte esses erros porque nós temos a possibilidade de ir na esfera maior, que no caso é o Ministério Público ou até mesmo o Ministério da Saúde, né?! E porque o que o Conselho recomenda é como se fosse uma lei, porque na verdade é o Controle Social falando, e sem o Controle Social na verdade não vem verba para o município da forma que vem hoje diretamente. Então o Controle Social nas cidades de grande porte é obrigatório. Por exemplo, nós não temos que estar ali como se estivesse fazendo favor para ninguém, nós somos eleitos pra estar ocupando esse espaço, é eleito por representantes dos usuários pra representá-los durante uma gestão, que é de dois anos, né [...]. (Isaías - ICS2). 
Percebe-se que, para Isaías, a participação em outros espaços de Controle Social possibilita uma avaliação mais ampla em relação à temática, pois ele cita diversos exemplos do que acredita ser a participação ativa da comunidade na política de saúde, ao contrário do que observa no órgão em que participa.

Questionado se há contato com a diretoria do HC-UFU, a fim de discutir a respeito das manifestações de usuários, o representante da ICS1 pontua que tal fato ocorre com pouca frequência. Declara, ainda, desconhecer o motivo, mostrando, de certa forma, que esta situação dificulta o trabalho:

Olha, esse contato é feito quando há necessidade de reuniões com a direção para que a gente peça a intervenção deles, a intercessão deles junto a gerencias para que nos ajude a dar resposta no tempo hábil, porém isso não tem acontecido. Eu não sei se é acúmulo de serviço ou se é falta de vontade. (Oscar - ICS1).

O representante da ICS1 relata que a maior dificuldade enfrentada está relacionada à devolutiva das manifestações dos usuários, pois elas não chegam de acordo com o prazo estabelecido:

[...] Dificuldade? Justamente na solução, na confiança que o pessoal deposita na ICS1, procurando a solução de seus problemas, e a maior dificuldade está nas respostas que nos são devolvidas no prazo indevido. Nós temos até dez dias úteis para responder para o usuário que nos busca, e essas respostas não estão vindo a contento. (Oscar - ICS1).

Ressalta, inclusive, que a busca por soluções imediatas é a maior solicitação das pessoas que se manifestam. Além disso, que esta não é a função deste espaço, fato que causa significativa descrença nos usuários do serviço.

Muitas vezes nós escutamos aqui falas assim: 'há, então a ICS1 não resolve nada'. Eles têm que ter consciência que a ICS1 não tem poder para resolver, nós somos o canal de comunicação entre o usuário e as autoridades competentes. (Oscar - ICS1).

Diante destas dificuldades, indagou-se acerca da existência ou não de apoio da Diretoria Geral do HC-UFU para a ICS1. Caso a resposta fosse positiva, foi perguntado como o representa o classifica, de que maneira ele acontece:

Excelente, apesar de que eles também estão nos relegando em segundo plano porque eles não fazem uma reunião semanal como era feita antigamente para saber a situação, mas nós mandamos mensalmente o relatório com a estatística do movimento da ICS1. Só reúne 
quando tem uma demanda grande ou para resolver alguma situação de emergência. (Oscar - ICS1).

Acerca desta fala percebe-se que, apesar de o representante da ICS1 classificar a relação entre esse espaço de participação e a Diretoria Geral do HC-UFU como excelente, ele pontua que não há diálogo. Embora o setor repasse relatório mensal para a Diretoria, somente é reservado espaço para reunião entre as partes em situações consideradas de emergência.

No que tange à outra ICS, o relato de Madalena deixa claro que este espaço não está ativo, pois não são realizadas reuniões há quatro anos. Entretanto, não esclarece o motivo desta inatividade, fato que pode ser interpretado como receio de alguma represália ou mesmo desconhecimento sobre esta questão; ela apenas explica que existe a proposta de a ICS3 voltar à ativa com uma reestruturação:

O Conselho hoje está desarticulado e ele está desestruturado, ele existe de fato no papel, de acordo com o último. Então, assim, não teve reunião nos últimos quatro anos, então agora que ele volta nessa reestruturação. (Madalena - ICS3).

Esta reestruturação é definida como uma reorganização determinada pelo Ministério da Saúde, na qual o novo espaço de participação deve seguir a mesma estrutura do anterior, agregando comunidade, trabalhadores etc.:

Hoje a reestruturação, ela está passando assim diferente, ela está seguindo uma determinação até do Ministério da Saúde, que tem uma portaria que é a de certificação do hospital. Então, quando o hospital é certificado para prestar os serviços para a Secretaria Municipal de Saúde, esse serviço de alta e média complexidade, existe uma portaria do Ministério da Saúde e o hospital cumpre essa portaria. Hoje, se eu não tiver enganado, são próximo de 70 itens que o hospital tem que cumprir. Ele assina um acordo e cumpre uma das determinações, agora é reestabelecer o Conselho, só que o Conselho não está nessa nova readequação, ele não vai ser esse Conselho, não é o Conselho, ele vai ser um Conselho de saúde local com a mesma estrutura [...]. Nós fizemos uma reunião onde foi feita uma convocação de toda a comunidade, o convite, é comunidade universitária, trabalhadores, comunidade externa, compareceram umas 50 pessoas, e ali tirou uma comissão, e essa comissão ficou responsável para estudar e elaborar um regimento interno para poder fazer uma adequação. Então essa é a estrutura, é o Conselho, ele volta a tomar corpo de volta, a funcionar. (Madalena - ICS3).

Esta determinação, prescrita pela Portaria Interministerial no 2.400, de 02 de outubro de 2007, prevê espaços de participação de docentes, discentes, funcionários e usuários para a efetivação do Controle Social nos 
Hospitais de Ensino: "Art. VII, b) XVI garantir mecanismos de participação e Controle Social no hospital, possibilitando representação docente, discente, de funcionários e de usuários." (BRASIL, 2007).

Em relação à articulação entre as Instâncias de Controle Social encontradas no HC-UFU, destaca-se que apenas um dos entrevistados considerou a sua existência atual:

Não, nunca nem foi citado, durante a as reuniões que a gente teve, nem foi citado sobre a Ouvidoria. (Isaías - ICS2).

Conselho... não, antigamente teve, agora não tem mais. A gente reunia, a gente tinha reuniões, agora... O que é Conad? Mais ou menos, quando alguém nos procura para alguma informação, muito raro... só quando existe alguma coisa que o hospital tem o interesse em saber que nos procura. Muito pouco. (Oscar - ICS1).

Olha, esse Conselho tem porque uma das ações é solicitar a participação da Ouvidoria. Como até membro do Conselho tinha um membro da Ouvidoria sim, porque o membro da Ouvidoria acaba recebendo muita informação do pessoal, seja ela por escrito. Tem pessoas que chega, escreve e fala, então acaba que tem muito isso. Então, assim, a participação da Ouvidoria é fundamental nessa ação. [...] Eles iam, participavam das reuniões, davam muitas sugestṍes, olha, traziam, gostavam muito de apresentar o fluxo das demandas, olha, nós tivemos uma distribuição de tantos questionários, tantos setores, então eles eram, eles são muito atuantes. (Madalena - ICS3).

A análise destas falas mostra certa contradição entre os relatos que representam as Instâncias de Controle Social no HC-UFU, demostrada pela alegação do entrevistado de que não conhece nenhuma das instâncias citadas. Isto ratifica o desconhecimento destes espaços pelos próprios trabaIhadores do HC-UFU.

Percebe-se que esta desarticulação das Instâncias de Controle Social se reflete na prática dos(as) profissionais do Serviço Social entrevistados(as) pois, uma vez questionados(as) sobre sua participação em algum espaço destinado a esse fim no interior do HC-UFU e/ou no município, eles(as) responderam:

No hospital não, quando eu estava no município sim, eu já participei de várias reuniões e foi na época muito proveitoso, mas aqui no hospital não. Reunião com os representantes da comunidade para discutir as questões relacionadas à saúde, depois a gente foi para uma reunião maior que foi na prefeitura, que foi no bairro, depois foi na prefeitura, depois ia para Belo Horizonte, enfim, a comissão, e até chegar na instância maior, mas eu participei só aqui no município. (Antônio assistente social do Pronto-Atendimento). 
Os/as profissionais do Serviço Social entrevistados no HC-UFU acreditam contribuir para a participação popular na política de saúde, mesmo que de maneira indireta, por meio de orientações sobre os direitos sociais. Acerca da relação estabelecida entre a ICS1 e o Serviço Social, Oscar enfatiza que isto existe, contudo, de maneira insuficiente.

Tem muito pouco, tem toda vez que nós precisamos de chamar porque eu acho que o usuário precisa ter um atendimento aqui no saguão do hospital de assistente social. Muitas vezes o usuário perdeu um paciente, está em crise, aí a gente chama, muito raramente aparece. Quando tem uma demanda, e olhe lá, muito pouco. Eu acho que precisava ter uma sala aqui no saguão do hospital do Serviço Social para dar essa assistência ao usuário. (Oscar - ICS1).

Em sua colocação, o representante da ICS1 também se confunde a respeito das atribuições referentes a estes(as) profissionais, enfatizando a necessidade de atendimentos que não condizem com os objetivos do Serviço Social. Tal fato fica expresso no trecho em que ele fala sobre a relevância dos(as) assistentes sociais em momentos de crise emocional como, por exemplo, na perda de familiares.

Os/as profissionais do Serviço Social explicam que seu contato com a ICS1 é demasiadamente pontual, sendo que alguns destacam que há comunicação com a ICS1 somente quando são solicitados(as). Além disso, todos(as) sublinham que fazem encaminhamentos dos usuários do HC-UFU, mas sem contato direto com o referido espaço.

Não, meu único contato... até hoje meu único contato é de encaminhamento para os usuários quando eles precisam, quando eles têm algumas queixas que a gente não consegue sanar no momento, que ele não se dá por satisfeito também com a minha orientação, aí eu oriento procurar o setor no sentido de melhorar as ações no hospital para que isso chegue na direção e isso possa melhorar. Mas eu ter contato com o setor, não, eu só faço encaminhamento para lá. Nunca fui procurada, não sei de trabalho lá, desconheço se tem um trabalho diferente além de captar as informações. (Maria - assistente social da Enfermaria).

Os usuários do HC-UFU alegaram desconhecer os serviços da ISC1; nenhum dos entrevistados disse ter realizado qualquer tipo de manifestação neste espaço. Quando indagado, um deles até mesmo definiu a ICS1 como uma espécie de direção:

Tenho medo de responder e depois sair errado, né?! É tipo, como é que fala? Esqueci, gente, é tipo de uma direção, um diretor mais ou menos, num é?! (Anderson - Enfermaria). 
Neste sentido, os representantes das ICS foram questionados acerca de quais elementos acreditam estar ausentes, no cenário atual, para que a comunidade participe mais dos espaços destinados ao Controle Social.

Seria mesmo uma divulgação tanto impressa como continuar colocando nas unidades, mas também a mídia está divulgando isso, né?! Porque tem que haver um envolvimento maior, porque as pessoas estão desacreditadas das ICS no geral porque eles têm uma visão que isso é só para questão política. Eles não têm essa visão que, por exemplo, o Conselho é soberano, é deliberativo, por exemplo, o municipal, então eles acham assim, 'ah, não adianta nada participar disso', né?! Então existe uma descrença da sociedade em relação, só que os que participam e vê a atuação, eles acabam gostando. Então muitos vão para pôr algum problema pessoal que está acontecendo com ele, para sabe de fato como que é ou até mesmo para fazer denúncia, e depois acabam ficando. (Isaías - ICS2).

O representante defende a necessidade de mais divulgação, fato que considera imprescindível, pois, como ilustrado anteriormente por meio das declarações dos usuários entrevistados, há demasiado desconhecimento sobre o Controle Social e suas instâncias representativas. Isaías também destaca certa desmotivação das pessoas em participar devido à crença de que estes espaços não são resolutivos. Apesar disso, afirma que os participantes conseguem perceber a sua relevância.

Acerca da contribuição que o Serviço Social pode oferecer para a efetivação do Controle Social, na percepção dos pacientes internados e dos representantes das Instâncias de Controle Social entrevistados, ressaltase que todos acreditam na sua existência. Contudo, os primeiros(as) alegam não saber como ela ocorre; os segundos enfatizam a integração da política da assistência social como elemento essencial para a sua realização:

Tem, eu acredito que sim, porque hoje a gente precisa aproximar mais as políticas sociais de tudo, porque o social, ele está muito ligado com a mudança das pessoas também porque, por exemplo, hoje em Uberlândia quantas pessoas não sabem o que é de direito na área social, tem gente que desconhece a Loas, por exemplo, e passa fome, sendo que tem o direito a recorrer, né?! A Loas, por exemplo, tem uma série de benefícios, tem gente... bolsa família sabe porque passa na televisão, mas ainda tem pessoas que não sabem sobre bolsa família, sobre um desconto, por exemplo, dependendo a renda, em um talão de energia, em um talão de água, né?! [...]. (Isaías - ICS2).

\section{Considerações finais}

A participação popular, inerente ao Controle Social, compõe-se principalmente dos Conselhos e Conferências, em âmbito externo ao am- 


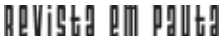

\} A CONTRIBUIÇÃO DO SERVIÇO SOCIAL PARA A EFETIVAÇÃO DO CONTROLE SOCIAL - MARTINS P. A. \}

biente hospitalar, sendo auxiliados pelo setor de Ouvidoria Geral do SUS. Estas instâncias são elaboradas com o intuito de possibilitar à população um espaço democrático para discussão, reflexão e deliberação das ações em saúde. É a partir delas que o Controle Social deve ser exercido prioritariamente, embora nos espaços de atenção da rede sua presença se faça concreta, apesar das inúmeras dificuldades para sua objetivação.

Nos documentos responsáveis por estruturar a Política de Saúde no Brasil, a ênfase na participação popular também segue o mesmo direcionamento. Em vista disso, considera-se o Controle Social como um dos seus eixos fundantes, o qual funciona como instrumento político na contribuição para a construção de uma legislação em sintonia com as reais necessidades da população.

Em meio à proposta de exercício do Controle Social e aos percalços encontrados para a sua efetivação, o/a assistente social, subsidiado(a) no Código de Ética e no Projeto Ético Político da categoria, propõe a luta conjunta com os usuários pelas políticas sociais na busca de legitimidade para a concretização da democracia. Sendo assim, o/a assistente social deve contribuir para a realização do Controle Social, apesar de as suas condições objetivas de trabalho nem sempre serem favoráveis. Portanto, a prática do(a) assistente social exige ações socioeducativas que mobilizem a comunidade, objetivando seu reconhecimento como sujeito coletivo em busca da efetivação dos seus direitos.

Na área hospitalar, todavia, este(a) profissional enfrenta limitações diversificadas para a execução de tal prerrogativa e, com frequência, restringe-se à execução de atividades individualizadas com caráter imediatista, o que pode ser considerado uma barreira no direcionamento e na concretização objetivada da sua proposta de trabalho. Esta situação também é confirmada na pesquisa de Vasconcelos (2009), o que reflete uma reiteração do fenômeno observado no HC-UFU. Ou seja, é uma lógica inerente ao pouco amadurecimento da Política Pública de Saúde e do distanciamento do ideário da Reforma Sanitária Brasileira.

Tendo em vista o comprometimento da categoria com a mobilização popular na luta pela garantia de direitos, o documento Parâmetros de atuação do assistente social na área da saúde recomenda aos/às assistentes sociais o desempenho de atividades que estimulem a organização popular, auxiliando no seu reconhecimento como sujeito coletivo com o dever e o direito de exercer o Controle Social.

A rotina de atuação dos(as) assistentes sociais que trabalham nas unidades de atendimento à urgência e emergência nos hospitais apresenta condições muito peculiares à especificidade da demanda, pois atendem um público deveras rotativo. Este, além de enfrentar diversos entraves na efetivação de seus direitos, na maioria das vezes está extremamente fragilizado com os danos causados pela doença (tanto físicos quanto emocionais); assim, não tem disposição ou desejo de buscar novos caminhos para a transformação da realidade que o cerca. 


\section{Referências}

BRASIL. Constituição da República Federativa do Brasil. Brasília, 1988. Disponível em: <http://www.planalto.gov.br/ccivil_03/constituicao/cons tituicao.htm>. Acesso em: 06 abr. 2013.

. Lei n. 8.080, de 19 de setembro de 1990. Dispõe sobre as condições para a promoção, proteção e recuperação da saúde, a organização e o funcionamento dos serviços correspondentes e dá outras providências. Brasília, 1990a. Disponível em: <http://www.planalto.gov.br/ccivil_03/leis/ |8080.htm>. Acesso em: 06 abr. 2013.

. Lei n. 8.142, de 28 de dezembro de 1990. Dispõe sobre a participação da comunidade na gestão do Sistema Único de Saúde (SUS) e sobre as transferências intergovernamentais de recursos financeiros na área da saúde e dá outras providências. Brasília, 1990b. Disponível em: <http:// www.planalto.gov.br/ccivil_03/leis/l8142.htm>. Acesso em: 06 abr. 2013.

. Ministério da educação; Ministério da saúde. Portaria interministerial n. 2.400, de 2 de outubro de 2007. Estabelece os requisitos para certificação de unidades hospitalares como hospitais de ensino. Brasília, 2007. Disponível em: <http://sistema.saude.sp.gov.br/sahe/documento/portaria/PI_2400 _021007.pdf >. Acesso em: 06 abr. 2013.

- Tribunal de Contas da União. Orientações para conselheiros de saúde. Brasília: TCU, 4aㅗ Secretaria de Controle Externo. 2010.

- Ministério da Saúde. Portal da Saúde. Conheça a ouvidoria. 22 abr. 2014. Disponível em: <http://portal.saude.gov.br/portal/saude/area .cfm?id_area=1003>. Acesso em: 06 out. 2014.

CFESS, Conselho Federal de Serviço Social. Código de ética profissional do assistente social. Brasília, 1993. Disponível em: <http://www.cfess.org.br/ arquivos/CEP_CFESS-SITE.pdf>. Acesso em: 18 jun. 2013.

. Parâmetros para atuação de assistentes sociais na Política de Saúde. Brasília, 2010.

CONSELHO NACIONAL DE SAÚDE. Aprova diretrizes e normas regulamentadoras de pesquisa envolvendo seres humanos. Resolução n. 466, de 12 de dezembro de 2012. Disponível em: <http://bvsms.saude.gov.br/bvs/ saudelegis/cns/2013/res0466_12_12_2012.html>. Acesso em: 06 abr. 2013. LOURENÇO, E. A. de S. Na trilha da saúde do trabalhador: a experiência de Franca. Franca (SP): Unesp-FHDSS. 2009.

MINAYO, M. C. de S. Pesquisa social: teoria, método e criatividade. Petrópolis (RJ): Vozes. 1999. 


\section{Revigtg a p palltg}

\} A CONTRIBUIÇÃO DO SERVIÇO SOCIAL PARA A EFETIVAÇÃO DO CONTROLE SOCIAL - MARTINS P. A. \}

UFU, Universidade Federal de Uberlândia. Conselho Universitário. Resolução $n^{\circ}$ 11/2010. Aprova o Regimento Interno do Hospital de Clínicas de Uberlândia e dá outras providências. Uberlândia, 2010a. Disponível em: <http://www.reitoria.ufu.br/consultaAtaResolucao.php? >. Acesso em: 18 jun. 2013.

. Hospital de Clínicas de Uberlândia. Conheça o HC. Apresentação. 29 set. 2010b. Disponível em: <http://www.hc.ufu.br/conteudo/apresen ta\%C3\%A7\%C3\%A3o>. Acesso em: 06 abr. 2013.

VASCONCELOS, A. M. A prática do Serviço Social: cotidiano, formação e alternativas na área da saúde. São Paulo: Cortez. 2009.

Recebido em 12 de janeiro de 2015

Aprovado para publicação em 02 de março de 2015. 